\title{
V. On a singular development of polarizing structure in the Crystalline lens after death; and on the cause, the prevention, and the cure of cataract
}

\author{
Sir David Brewster K.G.H. V.P.R.S. Ed.
}

To cite this article: Sir David Brewster K.G.H. V.P.R.S. Ed. (1838) V. On a singular development of polarizing structure in the Crystalline lens after death; and on the cause, the prevention, and the cure of cataract, Philosophical Magazine Series 3, 12:71-72, 22-27, DOI: 10.1080/14786443808649369

To link to this article: http://dx.doi.org/10.1080/14786443808649369

$$
\text { 曲 Published online: } 01 \text { Jun } 2009 .
$$

Submit your article to this journal ¿

\section{山 Article views: 2}

Q View related articles ¿ 
moistened hands, the intensity of the rapid succession of shocks will be found absolutely intolerable, even when the battery used consists of but two plates presenting each 6 or 8 square inches of surface.

This magnetic contact-breaker will, I flatter myself, be found eventually of service to the chemist for electrolytic purposes; whilst as affording a ready mode of applying voltaic electricity for medical purposes, I think it will be considered of considerable service as dispensing with manual labour, and affording currents of far greater intensity than can be obtained from several dozen, or even a far greater number of pairs of plates excited by strong acids, a process equally inconvenient and expensive.

In conclusion, I ought to observe that the application of a permanent magnet to effect the rupture of contact without manual labour is by no means original with me, although in justice to myself I must state, that when I first contrived the above-described instrument I was not aware of a similar principle having been adopted for this purpose. In the last number of Prof. Silliman's Journa! is a paper by Dr. Page describing several pieces of apparatus to be used with Dr. Henry's gigantic coils; one of these contrivances, ill-described however, consists of a bar of iron covered with a helix oscillating between the poles of a single permanent magnet, constituting, from my own experience, a very ineffective arrangement. To Dr. Page, however, must in justice be accorded the originality of the application of permanent magnets for the purpose of breaking contact.

I remain, my dear Sir, yours truly, 22, Wilmington Square, Nov. 2, 1837. GoldiNG BIRD.

To Richard Phillips, Esq., F.R.S. L. \& E., \&c.

N.B. The contact-breaker described in this letter was constructed for me by Mr. Neeves, of Great St. Andrew's Street, Holborn.

V. On a singular Development of Polarizing Structure in the Crystalline Lens after Death; and on the Cause, the Prevention, and the Cure of Cataract. By Sir David Brewster, K.G.H., V.P.R.S. Ed. *

$\mathrm{N}$ examining the changes which are produced by age in the polarizing structure of the crystalline lenses of animals,

I was induced to compare these changes with those which I

- From the Report of the Sixth Meeting of the British Association : Transactions of the Sections, pp. 16, 111. See Lond. and Edinb. Phil. Mag., vol. viii. pp. 193, 416 . 
conceived might take place, afte: death, when the lens was allowed to indurate in the air, or was preserved in a fluid medium. After many fruitless experiments I found that distilled water was the only fluid which did not affect the transparency of the capsule, and my observations were therefore made with lenses immersed in that fluid. The general polarizing structure of the crystalline in the sheep, horse, and cow, consists of three rings, each composed of four sectors of polarized light, the two innermost rings being positive like zircon, and the outermost negative, like calcareous spar. In other cases, especially when the lenses were taken from older animals, four rings were seen, the innermost of which was positive as before, and the rest negative and positive in succession.

I now placed a lens which gave three rings, in a glass trough containing distilled water, and I observed the changes which it experienced from day to day. These changes were such as I had not anticipated; but though $I$ have observed and delineated them under various modifications, I shall confine myself at present to the statement of the general result. There is a black ring between the two positive structures or luminous rings. After some hours' immersion in distilled water, this black ring becomes brotonish, and on the second day after the death of the animal, a faint blue ring of the first order makes its appearance in the middle of it, and its double refraction, as exhibited by its polarized tint, increases from day to day, till the tint reaches the rohite of the first order. Simultaneously with this change of colour, the breadth of this new ring gradually increases, encroaching slightly upon the inner positive ring, but considerably upon the second positive ring; so that the black or neutral ring which separates the two positive structures, and in the middle of which a new luminous ring is created, divides itself into two black neutral rings, the one advancing outwards, and diminishing the breadth as well as the intensity of the second series of positive sectors, and the other advancing inwards, and diminishing the breadth and intensity of the inner or central sectors. While these changes are going on, the outer luminous or negative ring advances inwards, encroaching also on the second positive ring.

Upon examining the character of the new luminous ring, the development of which has produced all these changes, I found it to be negative, so that at a certain stage of these variations we have a positive and a negative doubly refracting structure succeeding each other alternately, from the centre to the circumference of the lens, such as I have often observed in lenses taken from animals of greater age, and examined immediate]y after death. 
After this stage of perfect development, when there is a marked symmetry both in the relative size and polarizing in. tensities of the four series of sectors, the lens begins to break up. The new negative ring encroaches so much on the two positive ones, which it separates, that the outer one is sometimes completely extinguished, while the breadth and tint of the inner sectors are greatly diminished, so that the highest double refraction exists in the newly developed ring. In a day or two this ring also experiences a great change of distinctness and intensity, and the lens commonly bursts on the fifth or sixth day, sometimes in the direction of the septa or lines where its fibres have their origin and termination, and sometimes in other directions.

In order to give a general idea of the cause of these singular changes, I may state that the capsule which incloses the lens is a highly elastic membrane-that it absorbs distilled water abundantly - and that, in consequence of this property, the lens gradually increases in bulk, and becomes more globular, till the capsule bursts with the expansive force of the overgrown lens. That the reaction of the elastic capsule contributes to modify the polarizing structure of the interior mass, cannot admit of a doubt, as it is easy to prove that that structure is altered by mechanical pressure; but I cannot conceive how such a reaction could create a new negative structure between two positive ones, and produce the other phænomena which I have described. I have been led therefore to the opinion, that there is in the crystalline lens the germ of the perfect structure, or rather the capability of its being developed by the absorption of the aqueous humour; that this perfect structure is not produced till the animal frame is completely formed; and that when it begins to decay the lens changes its density and its focal length, and sometimes degenerates into that state which is characterized by hard and soft cataract.

The results, of which $I$ have now given an exceedingly brief notice, appear to me to afford a satisfactory explanation of those changes in the lens which terminate in cataract, a disease which seems to be more prevalent than in former times. Accidental circumstances have led me to study the progress of this disease in one peculiar case, in which it was arrested and cured; and $I$ am sanguine in the hope that a rational method of preventing, and even of stopping the progress of this alarming disease, before the laminæ of the lens have been greatly separated or decomposed, may be deduced from the preceding observations.

As the experiments, however, and views upon which this 
expectation is founded, are more of a physiological than of a physical nature, I am desirous of submitting an account of them to the Medical Section, that they may undergo that strict examination which they could receive only from the experience and science of that distinguished body.

On the Cause, the Prevention, and the Cure of Cataract.

Having submitted to the Physical Section an account of a singular change of structure produced by the action of distilled water upon the crystalline lens after death, Sir D. Brewster was desirous of communicating to the Medical Section some views which this, and previous observations, have led him to entertain respecting the cause and the prevention and cure of cataract.

"'The change of structure to which I have referred consists in the development of a negative polarizing band or ring between the two positive rings nearest the centre of the lens; the gradual encroachment of this new structure upon the original polarizing structure of the lens; and the final bursting of the lens after it had swelled to almost a globular form by the absorption of distilled water.

"As the crystalline lens floats in its capsule there can be no doubt that it is nourished by the absorption of the water and albumen of the aqueous humour, and that its healthy condition must depend on the relative proportion of these ingredients. When the water is in excess the lens will grow soft, and may even burst by its over absorption; and when the supply of water is too scanty, the lens will, as it were, dry and indurate, the fibres and laminæ formerly in optical contact will separate, and the light being reflected at their surfaces, the lens will necessarily exhibit that white opacity which constitutes the common cataract.

"' This defect in the healthy secretion of the aqueous humour, as well as the disposition of the lens to soften or to indurate by the excess or defect of water, may occur at any period of life, and may arise from the general state of health of the patient; but it is most likely to occur between the ages of 40 and 60 , when the lens is known to experience that change in its condition which requires the use of spectacles. At this period the eye requires to be carefully watched, and to be used with great caution; and if any symptoms appear of a separation of the fibres or lamina, those means should be adopted which, by improving the general health, are most: likely to restore the aqueous humour to: its usual state. Nothing is more easy than to determine at any time the sound state of the crystalline lens; and by the examination of a small Phil. Mag.S. 3. Vol. 12. No. 71. Jan. 1838. E 
luminous image placed at a distance, and the interposition of minute apertures and minute opake bodies of a spherical form, it is easy to ascertain the exact point of the crystalline where the fibres and laminæ have begun to separate, and to observe from day to day whether the disease is gaining ground or disappearing.

"In so far as I know, cataract in its early stages, when it may be stopped or cured, has never been studied by medical men; and even when it is discovered, and exhibits itself in white opacity, the oculist does not attempt to reunite the separating fibres, but waits with patience till the lens is ready to be couched or extracted.

" Considering cataract, therefore, as a disease which arises from the unhealthy secretion of the aqueous humour, I have no hesitation in saying that it may be resisted in its early stages, and in proof of this I may adduce the case of my own eye, in which the disease had made considerable progress. One evening I happened to fix my eye on a very bright Jight, and was surprised to see round the flame a series of brightly coloured prismatic images, arranged symmetrically and in reference to the septa to which the fibres of the lens are related. This phænomenon alarmed me greatly, as I bad observed the very same images in looking through the lenses of animals partially indurated, and in which the fibres had begun to separate. These images became more distinct from day to day, and lines of white light of an irregular triangular form afterwards made their appearance. By stopping out the bad parts of the lens by interposing a small opake body sufficient to prevent the light from falling upon it, the vision became perfect, and by placing an aperture of the same size in the same position, so as to make the light fall only on the diseased part of the lens, the vision entirely failed.

" Being now quite aware of the nature and locality of the disease though no opacity had taken place so as to appear externally, I paid the greatest attention to diet and regimen, and abstained from reading at night, and all exposure of the eyes to fatigue or strong lights. These precautions did not at first produce any decided change in the optical appearances occasioned by the disease; but in about eight months from its commencement I saw the coloured images and the luminous streaks disappear in a moment, indicating in the most unequivocal manner that the vacant space between the fibres or laminæ had been filled up with $\mathbf{a}$ fluid substance transmitted through the capsule from the aqueous humour. These changes took place at that period of life when the eye undergoes that change of condition which requires the use of glasses, and 
I have no doubt that the incipient separation of the laminæe would have terminated in confirmed cataract had it not been observed in time, and its progress arrested by the means already mentioned. Since that time the eye, though exposed to the hardest work, has preserved its strength, and is now as serviceable as it had ever been.

"If the cataract had made greater progress, and resisted the simple treatment which was employed, I should not have hesitated to puncture the cornea, in the expectation of changing the condition of the aqueous humour by its evacuation, or even of injecting distilled water or an albuminous solution into the aqueous cavity."

\section{On Tritiadide of Mercury. By Mr. Robent Hunt*.}

I AM not aware that any one has observed more than two combinations of iodine and mercury, the yellow iodide and the scarlet biniodide; therefore a short account of a third may not be uninteresting.

If with a saturated solution of the iodide of potassium we unite as much iodine as it will dissolve, and then add a sufficient quantity of the bichloride of mercury to separate the iodine of the salt, instead of the scarlet biniode, a purple-brown powder will be precipitated, which will be found to be one proportional of mercury combined with three proportionals of iodine, or

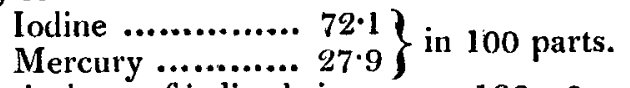

Three equivalents of iodine being ...... 126 $\times 3=378$

One equivalent of mercury................ 202

580 is its

equivalent number.

The tritiodide of mercury is soon resolved by exposure to the air into the biniodide, as it is also by alcohol, which separates one proportional of iodine. Heat likewise drives off a portion of the iodine, and the binary compound results. But if it is exposed in a strong glass tube filled with carbonic acid or the vapour of ather, and hermetically sealed, to the heat of a spirit flame, it sublimes in deep amber-coloured acicular crystals, which are tolerably permanent in the air.

It is soluble in hot chloride of sodium, from which on cooling black fibrous crystals form, which I suspect to be a compound of chloriodic acid and soda; but I have not yet had an opportunity of properly examining this compound.

* Communicated by the Author.

E 2 